\title{
КЛАССИФИКАЦИОННЫЙ ПОДХОД К ИНВЕСТИЦИОННЫМ РИСКАМ НА МЕЗОУРОВНЕ РЕГУЛИРОВАНИЯ
}

\author{
(c) 2019 Безденежных Вячеслав Михайлович \\ доктор экономических наук, профессор кафедры Анализа рисков и экономической безопасности \\ Финансовый университет при Правительстве РФ, Россия, Москва \\ E-mail:savrula@gmail.com \\ (c) 2019 Индарбаев Асхаб Алиавич \\ аспирант \\ Финансовый университет при Правительстве РФ, Россия, Москва \\ E-mail:askhab13@gmail.com
}

В статье определена актуальность управления инвестиционными рисками на мезо-уровне в тесной взаимосвязи с микро- и макро-уровнем, рассмотрены различные подходы к понятию инвестиционного риска и различные взгляды на классификацию факторов инвестиционных рисков. В результате предложено авторское определение инвестиционных рисков и авторский подход к классификации факторов инвестиционного риска. Предложенная классификация будет способствовать систематизации инвестиционного риска и повышать эффективность управления инвестиционными рисками мезо-уровня.

Ключевые слова: инвестиционный риск, мезо-уровень, факторы риска, классификация факторов инвестиционного риска.

Управление рисками для любых субъектов экономики носит необходимый объективный характер, а в особенности на мезоуровне регулирования является необходимым аспектом эффективного развития всей цепочки экономических социально-экономических отношений от макро- до микроуровня. Наличие методов и инструментов достоверного анализа и оценки факторов риска, а также возможность применения этого инструментария в целях нейтрализации их последствий, дает возможность системе устойчиво развиваться, прогнозировать свое развитие и повышать конкурентоспособность в масштабе национальной экономики и даже выходя за ее пределы.

Для обеспечения устойчивого развития национальной экономики в целях повышения экономической безопасности РФ и в связи с постоянно изменяющейся политической и экономической средой функционирования всей мировой системы, а также влияния экономических санкций на РФ со стороны западных стран, требуют максимальной защиты интересы экономической безопасности России и её национальной экономической структуры.

В последнее время все большую популярность приобретает проектное управление, особенно в отношении реализации стратегических

планов государства. С целью реализации стратегии развития государства, обеспечения ее экономической и национальной безопасности, необходимым является формирование системы управления рисками инвестиций на региональном уровне как наиболее важном элементе в общем регулировании эффективности развития экономики.

В российских условиях, особенно на региональном уровне, регулярным инвестиционным рискам сопутствуют колебания экономической и политической внешней и внутренней ситуации, а также дефицит инвестиционных ресурсов, что делает влияние регулярных рисков более непредсказуемым и появляется необходимость не только оценки самого риска, но и оценки вероятности появления того или иного вида риска.

В этой связи, на наш взгляд, было бы целесообразным показать возможности оценки региональных инвестиционных рисков, а также основные способы их минимизации на этапе первоначального распределения инвестиционных ресурсов. Инвестиционные риски в регионе, как правило, оцениваются по трем группам: кредитования, реализации инвестиционных проектов, возврата инвестиционных ресурсов. Помимо этого, риски могут быть оценены по уровню потерь. 
В регионе создается действенная система управления рисками, суть которой можно описать следующим образом.

С целью обеспечения приемлемого дохода на инвестируемые средства прогнозируемая ставка дохода на вложенные средства должна основываться на ставке рефинансирования и надбавке за риск, используемой при банковском кредитовании. Надбавка включает ожидаемые затраты по формированию инвестиционного портфеля и определенный доход на инвестированные средства для владельца инвестиционных ресурсов. Ожидаемые затраты, в свою очередь, включают надбавки за риски инвестирования и эксплуатационные затраты по мобилизации средств и осуществлению инвестирования. Эти затраты включают кредитный риск, риск процентной ставки, риск альтернативного выбора, риск изменения условий мобилизации фондов, риск ликвидности, административные издержки и доход на акционерный капитал. Для описания методов оценки желательно уточнить понятийный аппарат исследования.

Инвестиционный риск подразумевает под собой риск, обусловленный неопределенностями в инвестиционной сфере [1]. Упомянутые в данном определении неопределённости способны вызвать различные отклонения системы.

Другие авторы полагают, что в самом общем виде риск в может определяться как возможность возникновения потерь, которая вытекает из специфики природных явления или человеческих видов деятельности. Следовательно, в случае более детализированного изучения, риск может определяться как определенный уровень финансовых потерь, который выражается в следующих аспектах:

- в возможности не достижения поставленных целей;

- в неопределенности прогнозируемых результатов;

- в субъективности прогнозных оценок результатов [2].

Часть исследователей, определяет риск как экономическое явление, которое является основным элементом всех социально-экономических явлений и процессов, происходящих в организации, и способных вывести систему из равновесного состояния и, в результате, либо улучшить ее, либо привести к незапланированным убыткам, либо разрушить совсем [3].

Исходя из рассмотренных подходов к опре- делению риска и учитывая то, что мезо-экономические факторы риска не являются общими, а носят специфический характер, предложим уточненное определение инвестиционных рисков мезоуровня регулирования.

Инвестиционный риск мезоуровня регулирования предлагается определить, как возможную вероятность снижения инвестиционного дохода или возникновения убытков или нежелательных отклонений реализации инвестиционного проекта, реализуемого на мезоуровне.

В целях организации эффективной системы управления инвестиционными рисками в первую очередь стоит выявить основные факторы инвестиционного риска.

В современных литературных источниках существуют различные подходы к классификации инвестиционных факторов риска.

Так, например, один из авторов выделяет технологические инвестиционные риски, инвестиционные риски финансовой группы, инвестиционные риски политической группы, инвестиционные риски социальной группы, финансовая группа инвестиционных рисков, законодательно-правовая группа инвестиционных рисков [4].

В группу технологических рисков автор включает риски технологии процесса управления и производства, а также риски технического уровня применяемого оборудования. По нашему мнению, данный подход может привести к размыванию определенных факторов и их недоучету, что сможет снизить эффективность процесса управления инвестиционными рисками.

Герзелиева Ж.И.предлагает классифицировать риски инвестиционных проектов по трем критериям:

1. Функциональная группа, которая включает в себя стратегический, коммерческий, юридический, финансовые, маркетинговые, риски финансирования, операционные риски, риски форсмажорных обстоятельств, экологические риски.

2. По степени интеграции инвестиционного проекта в деятельность инвестора: индивидуальные, корпоративные и рыночные.

3. По элементам эффективности инвестиционных проектов - риски затрат и риски поступлений [5].

Предложенная классификация делает акцент на эффективность инвестиционного проекта, что является неотъемлемым и очень важным 
элементом управления проектами на всех стадиях его жизненного цикла, однако не учитывает технологические аспекты инвестиционного проектирования.

Изучив отдельные подходы к классификации факторов риска инвестиционных проектов, стоит рассмотреть авторский подход к классификации факторов риска инвестиционных проектов. В таблице 1 представлен авторский подход к классификации факторов риска инвестиционных проектов, основанный и дополняющий рассмотренные взгляды.

Опишем рассмотренные группы факторов инвестиционных рисков более подробно.

1. Технологические инвестиционные риски - связаны с технологическими особенностями реализации и управления инвестиционного проекта, а также технологией производства и организации труда проекта. Включают в себя также применяемые и внедряемые технологии в процессе реализации проекта, в том числе и технологические инновации.

2. Технические инвестиционные риски -подразумевают техническую оснащенность проекта, эффективность работы используемого оборудования, уровень автономности и автоматизации технологических и управленческих процессов и т.д.

Финансовые риски инвестиционного проекта - обусловлены факторами риска в финансовой сфере, которые могут включать в себя не эффективность финансового менеджмента про- екта, влияние различных внешних и внутренних экономических факторов на доходность проекта. Эффективность финансового менеджмента должна основываться на принципах экономического роста: внедрять современные методы и стили управления, инновационные процессы, обеспечивать работников заработной платой, соблюдать законность [6]. Проявляются в основном на поздних стадиях реализации проекта

3. Риски финансирования инвестиционного проекта может быть обусловлен недостаточностью финансирования инвестиционного проекта, прекращение финансирования по различным причинам (потеря интереса инвестора, изменение финансового положение в регионе и у инвестора, изменение политической конъюнктуры и т.п.). Данная группа рисков является труднопредсказуемой и малоуправляемой.

4. Политические инвестиционные риски могут быть вызваны политической ситуацией в стране или регионе. Наибольшее влияние имеют на инвестиционные проекты с международным участием. К данной группе рисков также относится санкционные ограничения, обострения взаимоотношений между правительствами различных стран. Одним из ярких примеров политического инвестиционного риска, являются финансовые потери туристического бизнеса в Грузии от прекращения авиасообщений с Россией. При анализе данной группы рисков стоит учитывать и прогнозировать политические взаимоотношения с другими странами. В груп-

Таблица 1. Классификация факторов риска инвестиционных проектов

\begin{tabular}{|c|l|l|}
\hline № п/п & \multicolumn{1}{|c|}{$\begin{array}{c}\text { Группа факторов } \\
\text { инвестиционных рисков }\end{array}$} & \multicolumn{1}{|c|}{ Краткое описание } \\
\hline 1 & Технологические & $\begin{array}{l}\text { Технология управления и организации производства, а также } \\
\text { применяемые и внедряемые технологии в процессе реализации } \\
\text { проекта, в том числе и технологические инновации. }\end{array}$ \\
\hline 2 & Технические & $\begin{array}{l}\text { Техническая оснащенность проекта, эффективность оборудова- } \\
\text { ния, уровень автоматизации, энергоемкоси и т.п. }\end{array}$ \\
\hline 3 & $\begin{array}{l}\text { Финансовые риски } \\
\text { инвестиционного проекта }\end{array}$ & $\begin{array}{l}\text { Неэффективность финансового менеджмента, внешние и вну- } \\
\text { тренние экономические факторы. }\end{array}$ \\
\hline 4 & $\begin{array}{l}\text { Риски финансирования } \\
\text { инвестиционного проекта }\end{array}$ & $\begin{array}{l}\text { недостаточность финансирования инвестиционного проекта } \\
\text { или полное прекращение финансирования проекта. }\end{array}$ \\
\hline 5 & $\begin{array}{l}\text { Политические инвестиционные } \\
\text { риски }\end{array}$ & $\begin{array}{l}\text { Политическая ситуация в стране, санкцинные ограничения, } \\
\text { изменение законодательства и его нестабильность, как внутри } \\
\text { страны, так и за рубежом. }\end{array}$ \\
\hline 6 & $\begin{array}{l}\text { Социально-психологические } \\
\text { инвестиционные риски }\end{array}$ & $\begin{array}{l}\text { Социальная напряженность в регионе, забастовки, межнацио- } \\
\text { нальные разногласия и конфликты, психологический климат в } \\
\text { компании и т.п. }\end{array}$ \\
\hline 7 & $\begin{array}{l}\text { Информационные риски } \\
\text { инвестиционного проекта }\end{array}$ & $\begin{array}{l}\text { Эффективность системы информационного обеспечения } \\
\text { управления проекта, доступность и достоверность информации, } \\
\text { эффективность рекламно-информационных кампаний и т.п. }\end{array}$ \\
\hline
\end{tabular}


пу политических рисков также стоит включить политико-правовые факторы риска, так как изменение законодательства и его нестабильность также отрицательно сказывается на приток инвестиций в регион.

5. Социально-психологические инвестиционные риски - включают в себя социальную напряженность в стране, забастовки, социальную политику государства, межнациональные разногласия и конфликты, психологическая остановка в коллективе компании реализующий инвестиционный проект, социально-психологическая обстановка в отрасли. Данная группа факторов риска способна вывести из равновесия систему управления и снизить эффективность реализации инвестиционного проекта. Забастовки могут вызвать потери времени, которые как минимум повлекут задержку во времени реализации проекта и появлении нового продукта на рынке, что может спровоцировать недовольство инвесторов. Данная группы факторов инвестиционного риска является достаточно сложно непредсказуемой в отношении прогнозирования и управления.

6. Информационные риски инвестиционного проекта - наличие и эффективность системы информационного обеспечения менеджмента проекта, доступность к необходимой информации для наиболее эффективной реализации проекта, достоверность информационного обеспечения, необходимый уровень рекламно-информационных кампаний и их эффективность. На сегодняшний момент наблю- дается стремительное развитие информационно-коммуникативных технологий [7].

Всё вышеперечисленные факторы риска во многом подрывают результативную инвестиционную деятельность [4] и негативно влияют на эффективность реализации и управления проектами, что приводит зачастую к закрытию проектов.

Следуя предложенному определению риска инвестиционного проекта и классификации факторов риска инвестиционных проектов можно определить ряд причин и факторов, способных сформировать риски снижения эффективности и результативности инвестиционных проектов. В первую очередь, к ним следует отнести дефекты системы менеджмента. Основными факторами инвестиционного риска мезо-управления является неэффективное административно-правовое, информационное и финансовое взаимодействие макро-, мезо- и микро-уровней хозяйственной системы. Акцент на факторы риска мезо-уровня обусловлен тем, что именно он является наиболее уязвимым с точки зрения возникновения различных факторов инвестиционного риска и в то же время наиболее управляемым, в отличие от макро-уровня.

Следовательно, система анализа, оценки и управления инвестиционными рисками мезоуровня должна быть выстроена с учетом всех перечисленных выше факторов, что будет повышать ее эффективность и снизит общий инвестиционный риск проекта.

\section{Библиографический список}

1. В.М. Безденежных, В.И. Авдийский Прогнозирование и управление рисками хозяйствующих субъектов: учебник / В.М. Безденежных, В.И. Авдийский.- Москва: КНОРУС, 2017. - 272 с.

2. Управление рисками: Учебное пособие/ Л.Н. Мамаева.- 2-е изд.- М.: Издательско-торговая корпорация «Дашков К», 2014.- С.11.

3. Капустина, Н.В. Методология управления развитием организации на основе риск-менеджмента: автореф. дис. ... д-ра экон. наук/Н.В. Капустина. -СПб., 2015. -350 с.

4. Архипова Ю.А. Риски в инвестиционной деятельности и способы их снижения // Молодой ученый. - 2015.№ 5.- C. 232-234. - URL https://moluch.ru/archive/85/15947/ (дата обращения: 31.08.2019).

5. Герзелиева Ж.И. Развитие подходов к определению, классификации и управлению рисками инвестиционных проектов // Российское предпринимательство. - 2016.- т. 17. - № 19. - С. 2495-2506. - doi: 10.18334/ rp.17.19.36623

6. Аничкина О.А., Капустина Н.В. Особенности становления и развития малых организаций пищевой промышленности [Текст] / Аничкина О.А., Капустина Н.В. // «Экономика и предпринимательство» 2014. № 6(47). с.624-628

7. Фоменко Н.М., Капустина Н.В. Электронно-сетевые инструменты как инновационная составляющая коммуникационных связей публичного управления / Фоменко Н.М., Капустина Н.В. // Государственное и муниципальное управление. Ученые записки СКАГС. 2017. № 4. С. 68-72. 